\title{
IDENTIFICAÇÃO E RESISTÊNCIA A ANTIMICROBIANOS DE ESPÉCIES DE Aeromonas MÓVEIS ISOLADAS DE PEIXES E AMBIENTES AQUÁTICOS
}

\author{
Identification and antimicrobial resistance of motile Aeromonas isolated \\ from fish and aquatic environment
}

\author{
Daniela Hirsch ${ }^{1}$, Delton José Pereira Júnior ${ }^{2}$, Priscila Vieira Rosa Logato ${ }^{3}$, \\ Roberta Hilsdorf Piccoli ${ }^{4}$, Henrique César Pereira Figueiredo ${ }^{5}$
}

\begin{abstract}
RESUMO
Com o objetivo de se verificar a diversidade de espécies de Aeromonas móveis e seu perfil de susceptibilidade a antimicrobianos em pisciculturas comerciais, foram selecionadas oito tilapiculturas localizadas na região do Alto Rio Grande, Minas Gerais. De cada propriedade foram coletadas três amostras de peixes em estádio de pré-abate (vivos e saudáveis), uma amostra de água do tanque e uma amostra da água de abastecimento do sistema. De cada peixe foram coletadas amostras de lavado superficial e do parênquima renal. Diluições seriadas adequadas de cada amostra foram plaqueadas em TSA-ampicilina (10 mg/l) e as amostras de rim em Ágar Sangue de cavalo a 5\%. A partir de colônias isoladas positivas para o teste da oxidase foram realizados testes para identificação do gênero (testes presuntivos) e das espécies de Aeromonas (testes bioquímicos). O perfil de antibiograma foi obtido pelo teste de difusão de discos de antibióticos em Ágar Mueller Hinton. Foram obtidos 75 isolados diferenciados em nove espécies de Aeromonas: A. jandaei, A. hydrophila, A. trota, A. caviae, A. sobria, A. eucrenophila, A. veronii bt veronii, A. schubertii, A. media, além de amostras classificadas como Aeromonas atípicas. Do total isolado, oito amostras foram provenientes da superfície corpórea de peixes, 14 da água de abastecimento e 53 da água do tanque. Não houve isolamento a partir dos espécimes de parênquima renal. Em relação ao perfil de resistência, $93 \%$ dos isolados foram resistentes à eritromicina, $36 \%$ à tetraciclina, $13 \%$ ao ác. nalidíxico, $9 \%$ à gentamicina, $8 \%$ à nitrofurantoína, $8 \%$ à canamicina, $5 \%$ à norfloxacina, $4 \%$ ao cloranfenicol e $3 \%$ às sulfonamidas. Dentre os isolados analisados, $43 \%$ apresentaram índice de múltipla resistência a antimicrobianos (MAR) igual ou superior a $22 \%$, ou seja, resistência a dois ou mais drogas das nove testadas. Os dados apontam para um risco iminente, tanto pelo isolamento de amostras potencialmente patogênicas a seres humanos quanto pelo perfil de multirresistência dos isolados.
\end{abstract}

Termos para indexação: Aeromonas sp., resistência a antimicrobianos, tilápia.

\begin{abstract}
This experiment was done with the objective to verify the diversity of motile Aeromonas species and their antibiotic susceptibility profiles. A total of eight commercial producers of tilapia located in the Alto Rio Grande region of Minas Gerais state were selected for this experiment. The collected samples were three fish, one sample of pond water and one sample of water used in filling the pond. Suitable dilutions of the washed surface of the fish and water samples were scattered in TSA supplemented with ampicilin (10mg/l). Kidney samples were streaked in Horse Blood Agar. Isolated colonies oxidase positive, were submitted of tests for identification of the species of Aeromonas (presumptive and biochemical tests). The antibiogram profile of the isolated samples was obtained through a diffusion test of antibiotic disks in Mueller Hinton Agar. Were obtained 75 different isolates in nine species of Aeromonas: A. jandaei, A. hydrophila, A. trota, A. caviae, A. sobria, A. eucrenophila, A. veronii bv veronii, A. schubertii, A. media, and samples classified like atypical Aeromonas. Of the total isolations, eight samples were taken from the corporal surface of the fish, 14 from the water source and 53 from the pond water. There was no isolation of the renal tissue. In relation to the resistance profile, $93 \%$ of the isolated samples were resistant to erythromycin, $36 \%$ to tetracycline, $13 \%$ to nalidixic acid, $9 \%$ to gentamicin, $8 \%$ to nitrofurantoin, $8 \%$ to kanamycin, $5 \%$ to norfloxacin, $4 \%$ to chloramphenicol and $3 \%$ to sulfonamides. Among the isolated samples analyzed, 42,66\% presented a MAR index (Multiple Antibiotic Resistance Index) equal to or superior to $22,2 \%$. It was concluded that the isolation of potentially pathogenic bacterial species, with multiresistant antibiotic traits may be a risk to human food chain.
\end{abstract}

Index terms: Aeromonas sp., antimicrobial resistance, tilapia.

(Recebido para publicação em 17 de agosto de 2004 e aprovado em 17 de agosto de 2005)

${ }^{1} \mathrm{MSc}$., Laboratório de Doenças de Organismos Aquáticos - Departamento de Medicina Veterinária - Universidade Federal de Lavras/UFLA ${ }^{2}$ Médico Veterinário, Laboratório de Doenças de Organismos Aquáticos - Departamento de Medicina Veterinária - Universidade Federal de Lavras/UFLA - Cx. P. 3037 - 37200-000 - Lavras, MG.

${ }^{3}$ DSc., Setor de Aqüicultura - Departamento de Zootecnia - Universidade Federal de Lavras/UFLA - Cx. P. 3037 - $37200-000$ - Lavras, MG.

${ }^{4}$ DSc., Laboratório de Microbiologia de Alimentos - Departamento de Ciências dos Alimentos - Universidade Federal de Lavras/UFLA . Cx. P. 3037 37200-000 - Lavras, MG.

${ }^{5}$ DSc., Laboratório de Doenças de Organismos Aquáticos - Departamento de Medicina Veterinária - Universidade Federal de Lavras/UFLA - Cx. P. 3037 -

37200-000 - Lavras, MG - henrique@ufla.br 


\section{INTRODUÇÃO}

A piscicultura brasileira vem apresentando grande intensificação da produção nos últimos anos, tendo na tilápia nilótica (Oreochromis niloticus, Linaeus, 1766) uma das principais espécies cultivadas. Esta intensificação pode contribuir para o surgimento de doenças, devido à elevada densidade populacional, alta taxa de matéria orgânica e baixos níveis de oxigênio dissolvido.

Levando em consideração o aumento do risco de surgimento de doenças em pisciculturas intensivas, as bactérias do gênero Aeromonas têm assumido, nos últimos anos, uma maior importância nos diagnósticos de doenças de peixes, muitas vezes aparecendo como agente primário causador de lesões ulcerativas e septicemia hemorrágica em peixes de água doce (GHENGHESH et al., 2001; SAHA \& PAL, 2002; SOUZA \& SILVA-SOUZA, 2001), acarretando perdas na produção e na qualidade do pescado (RADU et al., 2003; VIVEKANADHAN et al., 2002).

Algumas espécies de Aeromonas têm sido associadas a doenças em seres humanos, sendo classificadas pela OMS (2003) como patógenos veiculados pela água e por alimentos contaminados, de interesse emergente à saúde pública (HEUZENROEDER et al., 1999; MARTINS et al., 2002; MERINO et al., 1995). Isolamentos de Aeromonas foram realizados a partir de vários alimentos, como por exemplo, leite e derivados, carcaças de frangos, vegetais e pescado (BANHART \& PANCORBO, 1992; FREITAS et al., 1993; GONZÁLEZ et al., 2001; GRAN et al., 2003; MCMAHON \& WILSON, 2001; PETTIBONE et al., 1996; RADU et al., 2003; SAAD et al., 1995; SOUZA \& SILVA-SOUZA, 2001; SUGITA et al., 1995; VIVEKANADHAN et al., 2002).

Outro aspecto importante relacionado à intensificação dos sistemas de criação de peixes é o uso crescente de antimicrobianos na profilaxia e no tratamento de doenças, o que tem gerado um aumento global da resistência bacteriana a múltiplas drogas, inclusive entre as espécies de Aeromonas (CHAUDHURY et al., 1996). A associação da múltipla resistência a diferentes antimicrobianos com a transferência horizontal potencial de genes de resistência entre bactérias filogeneticamente próximas ou não, é outra realidade preocupante (RHODES et al., 2000; SCHMIDT et al., 2001).

Supõe-se que a distribuição das espécies de Aeromonas em pisciculturas brasileiras e o perfil de resistência a antimicrobianos desses isolados sejam desconhecidos. Portanto, com este trabalho, buscou-se verificar a diversidade de espécies de Aeromonas em diferentes tilapiculturas localizadas na região do Alto Rio
Grande, Minas Gerais, Brasil e caracterizar os isolados quanto ao perfil de resistência antimicrobiana.

\section{MATERIALE MÉTODOS}

a) Seleção das propriedades: foram amostradas oito pisciculturas com cultivo de tilápias do Nilo (Oreochromis niloticus), localizadas na região do Alto Rio Grande, Minas Gerais. As propriedades foram nomeadas em A, B, C, D, F, $\mathrm{G}$ e $\mathrm{H}$. Todas as oito propriedades estudadas adotavam o sistema de recria e engorda em tanques de terra e apresentavam condições similares de manejo, utilizando ração comercial e a compra de alevinos de empresas multiplicadoras localizadas no Estado de Minas Gerais (com exceção da propriedade $\mathrm{C}$, que produzia seus próprios alevinos). Como pré-requisito para a coleta, nenhuma das propriedades apresentava problemas relacionados a doenças infecciosas. Nenhuma das propriedades informou o uso do controle de qualidade da água $(\mathrm{pH}$, oxigênio dissolvido e temperatura). Em todas as propriedades a água de abastecimento do sistema é proveniente de nascentes.

b) Coleta das amostras: de cada unidade produtora, um tanque de terra foi selecionado, de onde foram amostradas a água do tanque, do canal de abastecimento e peixes em estádio de pré-abate.

c) Isolamento a partir das amostras de água: as amostras foram coletadas em frascos estéreis, na porção de $500 \mathrm{~mL}$ cada, e transportadas ao laboratório a $4^{\circ} \mathrm{C}$ em caixas de isopor com gelo. $\mathrm{O}$ isolamento de Aeromonas foi feito mediante diluições seriadas (o inóculo é diluído à décima potência várias vezes, visando diminuir a quantidade de bactérias por mililitro para facilitar o isolamento) da água do tanque e de abastecimento. As diluições consideradas adequadas em pré-experimento (as quais geraram de 30 a 300 colônias por placas) foram plaqueadas em Ágar Soja Tripticaseína (TSA, Biolife, Itália) suplementado com ampicilina (Sigma) na concentração de $10 \mathrm{mg} / \mathrm{l}$. A incubação foi a $30^{\circ} \mathrm{C}$ por 24 horas. Das placas com crescimento de 30 a 300 colônias, 10 colônias com morfotipos diferentes e positivas para o teste da oxidase foram submetidas aos testes presuntivos para o gênero Aeromonas. Para validação da metodologia de identificação foi testada a amostra de referência Aeromonas hydrophila ATCC 7966.

d) Isolamento a partir das amostras de tilápias: foram coletadas três tilápias em cada propriedade, transportadas vivas para o laboratório em caixas de isopor contendo água do próprio tanque de cultivo. Após o sacrifício dos animais (dessensibilização por hipotermia), foi realizada a lavagem da superfície corpórea (HARRIGAN,

Ciênc. agrotec., Lavras, v. 30, n. 6, p. 1211-1217, nov./dez., 2006 
1998), em sacos plásticos estéreis contendo água peptonada estéril. Após a diluição seriada dos lavados superficiais, alíquotas das diluições foram semeadas em placas de Petri contendo TSA-Amp e incubadas a $30^{\circ} \mathrm{C}$ por 24 horas. Das placas com crescimento de 30 a 300 colônias, 10 colônias com morfotipos diferentes e positivas para o teste da oxidase foram submetidas aos testes presuntivos para o gênero Aeromonas. A obtenção asséptica de amostras de rim de cada peixe foi procedida seguindo as recomendações do OIE (2003). Após a amostragem da superfície corpórea, as escamas foram removidas mecanicamente, fez-se desinfecção do tegumento com álcool iodado. Foi realizada, então, uma incisão na porção dorsal média das tilápias e coletou-se o parênquima renal por "swab" estéril. O material coletado foi semeado em placas contendo Ágar Sangue de cavalo a $5 \%$ e a incubação foi realizada a $30^{\circ} \mathrm{C}$, por 24 horas. Todas as colônias isoladas foram submetidas aos testes presuntivos para o gênero Aeromonas.

e) Identificação presuntiva do gênero: com todos os isolados considerados positivos para o teste da oxidase foram realizados os testes de coloração de Gram, morfologia, catalase e fermentação da dextrina, testes estes que identificam presuntivamente o gênero.

f) Identificação bioquímica das espécies: os isolados considerados cocobastonetes Gram negativos, catalase positivos e fermentadores de dextrina foram então submetidos aos testes de fermentação de glicose, sacarose, manitol, salicina, trealose e arabinose, hidrólise de esculina, produção de acetoína e utilização dos aminoácidos lisina, arginina e ornitina (BERGEY'S..., 1994; JANDA \& ABBOTT, 1998). Os isolados que apresentaram variação em pelo menos três testes de identificação da espécie foram considerados Aeromonas atípicas, conforme classificação adotada por Freitas et al. (1993).

g) Determinação do perfil de resistência aos antimicrobianos: foi utilizado o método de difusão de discos de antimicrobianos (método de Bäuer-Kirby) em Ágar Müeller-Hinton (Merck, USA) (NCCLS, 1990). Foram testados os antimicrobianos: gentamicina 10 ìg, tetraciclina 30 ìg, eritromicina 15 ìg, sulfonamidas 300 ìg, ácido nalidíxico 30 ìg, cloranfenicol 30 ìg, nitrofurantoína 300 ìg, canamicina 30 ìg e norfloxacina 10 ìg (Cecon, Brasil). Para validação da metodologia foram testadas as amostras de referência Staphylococcus aureus ATCC 25923 e Pseudomonas aeruginosa ATCC 27853.

h) Determinação do índice de múltipla resistência a antimicrobianos (índice MAR): foi calculado como o número de antimicrobianos ao qual determinado isolado foi resistente sobre o número total testado (nove, nesse caso), multiplicando-se o valor final por 100 para obtenção dos resultados em percentuais (KRUMPERMAN, 1983).

\section{RESULTADOS E DISCUSSÃO}

De todas as propriedades coletadas houve isolamento de pelo menos duas espécies de Aeromonas (Tabela 1). Foram feitos 75 isolamentos diferenciados em nove espécies móveis: Aeromonas jandaei (26,67\%), A. hydrophila $(25,33 \%)$, A. atípica $(18,67 \%)$, A. trota (10,67\%), A. caviae (6,67\%), A. sobria (4\%), A. eucrenophila (2,67\%), A veronii bt veronii $(2,67 \%)$ e $A$. schubertii (1,33\%), além de uma espécie não-móvel: $A$. media $(1,33 \%)$.

Do total isolado, 14 (19\%) foram provenientes da água de abastecimento (oito identificados como $A$. hydrophila, quatro como $A$. atípica, uma como $A$. jandaei e uma como A. eucrenophila); 53 (70\%) advindos da água do tanque (dezesseis identificados como A. jandaei, onze como A. hydrophila, dez como A. atípica, cinco como A. trota, cinco como A. caviae, dois como A. veronii bt veronii, e um isolado de cada espécie: $A$. eucrenophila, A. media, A. sobria e A. schubertii) e 8 (11\%) oriundos da superfície corpórea de peixes (A. trota, três isolados; A. jandaei, três isolados e A. sobria, dois isolados). Não houve isolamento a partir do parênquima renal.

A ampla distribuição de diferentes espécies entre as propriedades estudadas é relevante devido ao fato de que foram encontradas espécies potencialmente patogênicas aos peixes (A. hydrophila, A.sobria, A.veronii, A. caviae, A. schubertii), o que, perante os manejos inadequados das pisciculturas (densidade populacional em desacordo com a máxima permitida, manipulação exagerada dos animais, alimentação inadequada, etc) gera o risco de surgimento de doenças. Foram isoladas também espécies potencialmente patogênicas a seres humanos (A. hydrophila, A.sobria, A. caviae, A. veronii bt veronii, A. schubertii, e $A$. jandaei), implicando em risco ao consumidor. Isolados não-patogênicos também foram identificados (A. media, A. trota e A. eucrenophila).

Chaudhury et al. (1996) e Ghenghesh et al. (2001), também encontraram diversidade similar de espécies de Aeromonas, ao estudarem águas de rios. Pela diversidade de espécies de Aeromonas observada, é provável que a água de abastecimento esteja funcionando como veículo de doenças para os plantéis. 
TABELA 1 - Quantidade de isolados de Aeromonas sp. obtidos a partir de amostras de peixes e de ambientes de cultivo de Tilápias, relacionados às diferentes propriedades coletadas.

\begin{tabular}{lccccccccc}
\hline & \multicolumn{1}{c}{ Propriedades } & \\
\cline { 2 - 8 } \multicolumn{1}{c}{ Espécies } & A & B & C & D & E & F & G & H & Total \\
\hline A. jandaei & 2 & 2 & 3 & 3 & 1 & 3 & 3 & 3 & 20 \\
A. hydrophila & 6 & 0 & 1 & 0 & 3 & 1 & 4 & 4 & 19 \\
A. atípica & 1 & 0 & 1 & 0 & 2 & 2 & 4 & 4 & 14 \\
A. trota & 2 & 1 & 1 & 0 & 0 & 3 & 1 & 0 & 8 \\
A. caviae & 0 & 0 & 0 & 0 & 0 & 5 & 0 & 0 & 5 \\
A. sobria & 0 & 0 & 2 & 0 & 1 & 0 & 0 & 0 & 3 \\
A. eucrenophila & 1 & 0 & 1 & 0 & 0 & 0 & 0 & 0 & 2 \\
A veronii & 0 & 0 & 0 & 1 & 1 & 0 & 0 & 0 & 2 \\
A. media & 0 & 1 & 0 & 0 & 0 & 0 & 0 & 0 & 1 \\
A. schubertii & 0 & 0 & 0 & 0 & 0 & 0 & 0 & 1 & 1 \\
\hline Total & 12 & 4 & 9 & 4 & 8 & 14 & 12 & 12 & 75 \\
\hline
\end{tabular}

Das amostras de água dos tanques de criação foram obtidos não somente o maior percentual de isolamento, como também a maior diversidade de espécies isoladas. Das três espécies isoladas da superfície corpórea dos peixes, nenhuma é considerada patogênica entretanto, Aeromonas sobria e A. jandaei possuem potencial patogênico para seres humanos (OMS, 2003), o que representa risco de contaminação do pescado e, conseqüentemente, do consumidor. Aeromonas hydrophila é a espécie mais associada a infecções em organismos aquáticos e a sua baixa freqüência de isolamento da superfície corpórea dos peixes analisados pode ser devida ao histórico de ausência de doenças nos plantéis.

Em relação ao perfil de resistência, 70 isolados do total obtido foram resistentes à eritromicina, 27 isolados à tetraciclina, dez isolados ao ácido nalidíxico, sete isolados à gentamicina, seis isolados à nitrofurantoína, seis isolados à canamicina, quatro isolados à norfloxacina, três isolados ao cloranfenicol e dois isolados às sulfonamidas.

A elevada freqüência de resistência para eritromicina está de acordo com estudos de Chaudhury et al. (1996), Pettibone et al. (1996), Radu et al. (2003) e Saha \& Pal (2002). Quanto à resistência à tetraciclina, gentamicina e canamicina, outros trabalhos (GHENGHESH et al., 2001; SON et al., 1997; VIVEKANANDHAN et al., 2002) relatam frequiências de resistência superiores às descritas para os isolados analisados. Os dados de resistência ao cloranfenicol, à nitrofurantoína e às sulfonamidas são extremamente variáveis dentro do gênero, não havendo parâmetro a ser considerado.

A resistência às quinolonas, como o ácido nalidíxico e a norfloxacina, é considerada cromossômica e não devido a elementos genéticos móveis, advinda da pressão de seleção de isolados resistentes frente às drogas (GOÑIURRIZA et al., 2000) ou ainda à multiplicação de clones resistentes (KLUGMAN, 2003). Portanto, a resistência encontrada em isolados obtidos da superfície corpórea dos peixes e da água do tanque pode ter sido proveniente dos alevinos ou da ração, já que não foi relatado o uso de antimicrobianos nas propriedades estudadas.

Dos 75 isolados, $32(42,66 \%)$ apresentaram índice MAR igual ou superior a $22,2 \%$, ou seja, resistência a 2 ou mais drogas das 9 testadas, sendo que foram obtidos 16 isolados com índice MAR de 22,2\%, seis isolados com $33,3 \%$, cinco isolados com $44,4 \%$, três isolados com $55,5 \%$, um isolado com $66,6 \%$ e outro com $77,7 \%$.

Os resultados dos índices MAR para cada espécie isolada (Tabela 2) demonstram índices médios superiores a $20 \%$, ou seja, resistência a, no mínimo, dois dos nove antimicrobianos testados, para amostras de Aeromonas caviae e A. trota. A presença de tais aeromonas potencializa o risco de difusão de genes de resistência entre as populações bacterianas de ambientes aquáticos, quer seja sob a forma de plasmídeos, quanto por transposons (KRUMPERMAN, 1983; SCHMIDT et al., 2000). 
TABELA 2 - Índices médios de múltipla resistência a antimicrobianos de Aeromonas isoladas de peixes e de ambientes de cultivo de Tilápia.

\begin{tabular}{lccc}
\hline Espécies Isoladas & Total de Isolados & Total de Resistentes* & $\begin{array}{c}\text { MAR } \\
\text { (média } \pm \mathbf{s})\end{array}$ \\
\hline Aeromonas caviae & 5 & 5 & $39,9 \% \pm 0$ \\
A. trota & 8 & 7 & $39,2 \% \pm 21$ \\
A. hydrophila & 19 & 19 & $18,3 \% \pm 13$ \\
A. jandaei & 20 & 18 & $17,5 \% \pm 11,6$ \\
A. eucrenophila & 2 & 2 & $16,6 \% \pm 7,8$ \\
A. sobria & 3 & 3 & $16,6 \% \pm 7,8$ \\
A. media & 1 & 1 & $11,1 \% \pm 0$ \\
A. veronii & 2 & 2 & $11,1 \% \pm 0$ \\
A. schubertii & 1 & 1 & $11,1 \% \pm 0$ \\
A. atípicas & 14 & 12 & - \\
\hline Total & 75 & 70 &
\end{tabular}

* número de isolados resistentes a pelo menos um antimicrobiano, dentro da espécie.

Quando se observa o índice MAR de cada amostra individualmente, o risco de difusão de genes de resistência se torna mais caracterizado. Foram obtidos isolados com índices MAR elevados, como um de Aeromonas trota, da propriedade A, isolado a partir da superfície do peixe e que apresentou índice MAR de 55,5\%, além de um isolado de $A$. jandaei proveniente da água do tanque da propriedade $\mathrm{A}$, que apresentou $77,7 \%$. Na propriedade $\mathrm{B}$, um isolado de $A$. trota obtido da superfície de peixe apresentou índice de 66,6\%. De todos os 75 isolados, apenas cinco apresentaram índices MAR elevados (acima de 44,4\%). Porém, entre estes cinco isolados, dois foram obtidos a partir das amostras do lavado superficial das tilápias. Este fato demonstra que esses isolados multirresistentes, se veiculados aos consumidores pelo pescado contaminado, podem estar transferindo genes de resistência à microbiota intestinal do mesmo.

\section{CONCLUSÕES}

Foi demonstrado que é grande a diversidade de espécies de Aeromonas em ambientes de piscicultura e que diversos isolados apresentam-se resistentes a antibióticos, mesmo sem o uso de tais substâncias para o controle de doenças infecciosas.

\section{REFERÊNCIAS BIBLIOGRÁFICAS}

BANHART, H. M.; PANCORBO, O. C. Cytotoxity and antibiotic-resistance profiles of Aeromonas hydrophila isolates from a broiler processing operation. Journal of
Food Protection, Des Moines, v. 55, n. 2, p. 108-112, Feb. 1992.

BERGEY'S mannual of determinative bacteriology. 9. ed. Baltimore: Willians \& Willians, 1994. 787 p.

CHAUDHURY, A.; NATH, G.; SHUKLA, B. N.; SANYAL, S. C. Biochemical characterization, enteropathogenicity and antimicrobial resistance plasmids of clinical and environmental Aeromonas isolates. Journal of Medical Microbiology, [S.1.], v. 44, n. 6, p. 434-437, 1996.

FREITAS, A. C.; NUNES, M. P.; MILHOMEM, A. M.; RICCIARDI, I. D. Occurrence and characterization of Aeromonas species in pasteurized milk and white cheese in Rio de Janeiro, Brazil. Journal of Food Protection, Des Moines, v. 56, n. 1, p. 62-65, Jan. 1993.

GHENGHESH, K. S.; EL-GHODBAN, A.; DKAKNI, R.; ABEID, S.; ALTOMI, A.; TAHRUNI, A.; MARIALIGETI, K. Prevalence, species differenciation, haemolytic activity, and antibiotic susceptibility of aeromonads in untreated well water. Memórias do Instituto Oswaldo Cruz, Rio de Janeiro, v. 96, n. 2, p. 169-173, Feb. 2001.

GOÑI-URRIZA, M.; CAPDEPUY, M.;ARPIN, C.; RAYMOND, N.; CAUMETTE, P.; QUENTIN, C. Impact of na urban effluent on antibiotic resistance of riverine Enterobacteriaceae and Aeromonas spp. Applied and Environmental Microbiology, Washington, v. 66, n. 1, p. 125-132, Jan. 2000. 
GONZÁLEZ, C. J.; SANTOS, J. A.; GARCÍA-LOPEZ, M. L.; GONZÁLEZ, N.; OTERO, A. Mesophilic aeromonads in wild and aquacultured freshwater fish. Journal of Food Protection, Des Moines, v. 64, n. 5, p. 687-691, 2001.

GRAN, H. M.; WETLESEN, A.; MUTUKUMIRA, A. N.; RUKURE, G.; NARVHUS, J. A. Occurrence of pathogenic bacteria in raw milk, cultured pasteurized milk and naturally soured milk produced at small-scale dairies in Zimbabwe. Food Control, [S.1.], v. 14, p. 539-544, 2003.

HARRIGAN, W. F. Laboratory methods in food microbiology. 3. ed. San Diego: Academic, 1998.

HEUZENROEDER, M. W.; WONG C. Y. F.; FLOWER, R. L. P. Distribution of two hemolytic toxin genes in clinical and environmental isolates from Aeromonas spp.: correlation with virulence in a suckling mouse model. FEMS Microbial Letters, Amsterdam, v. 174, p. 131-136, 1999.

JANDA, J. M.; ABBOTT, S. Evolving concepts regarding the genus Aeromonas: an expanding panorama os species, diseases presentations, and unanswered questions. Clinical Infectious Diseases, [S.1.], v. 27, p. 332-344, 1998.

KLUGMAN, K. P. The role of clonality in the global spread of fluoroquinolone-resistant bacteria. Clinical Infectious Diseases, [S.I.], v. 36, n. 15, p. 783-785, Mar. 2003.

KRUMPERMAN, P. H. Multiple antibiotic resistance indexing of Escherichia coli to identify high-risk sources of fecal contamination of foods. Applied and Environmental Microbiology, Washington, v. 46, n. 1, p. 165-170, July 1983.

MARTINS, L. M.; MARQUEZ, R. F.; YANO, T. Incidence of toxic Aeromonas isolated from food and human infection. FEMS Immunology and Medical Microbiology, [S.1.], v. 32, p. 237-242, 2002.

MCMAHON, M. A. S.; WILSON, I. G. The occurrence of enteric pathogens and Aeromonas species in organic vegetables. International Journal of Food Microbiology, Amsterdam, v. 70, p. 155-162, 2001.

MERINO, S.; RUBIRES, X.; KNOCHEL, S.; TOMÁS, J. M. Emerging pathogens: Aeromonas spp. International Journal of Food Microbiology, Amsterdam, v. 28, p. 157168, 1995.
NATIONAL COMMITTEE FOR CLINICAL LABORATORY STUDIES. Performance standards for antimicrobial disk susceptibility tests. 4. ed. Vilanova: NCCLS, 1990. (NCCLS document M2-A4).

OFFICE INTERNATIONAL DES EPIZOOTIES. Diagnostic manual for aquatic animal diseases. Paris: OIE, 2003. chapt. I.1.B.

ORGANIZAÇÃO MUNDIAL DA SAÚDE. Guidelines for drinking water quality. 3. ed. 2003. Disponível em: <http:/ 1/www.who.int/docstore/watersanitation health/GDWQ Updating/draftguidel/draftchap 7. htm > Acesso em: 11 maio 2004 .

PETTIBONE, G. W.; MEAR, J. P.; SAMPSELL, B. M. Incidence of antibiotic and metal resistance and plasmid carriage in Aeromonas isolated from brown bullhead (Ictalurus nebulosus). Letters in Applied Microbiology, Oxford, v. 23, p. 234-240, 1996.

RADU, S.; AHMAD, N.; LING, F. H.; REEZAL, A. Prevalence and resistance to antibiotics for Aeromonas species from retail fish in Malaysia. International Journal of Food Microbiology, Amsterdam, v. 81, p. 261-266, 2003.

RHODES, G.; HUYS, G.; SWINGS, P. M.; MCGANN, P.; HINEY, M.; SMITH, P.; PICKUP, R. W. Distribution of oxitetracycline resistance plasmids between aeromonads in hospital and aquaculture environments: implication of Tn1721 in dissemination of the tetracycline resistance determinant Tet A. Apllied and Environmental Microbiology, Washington, v. 66, p. 3883-3890, Sept. 2000.

SAAD, S. M. I.; IARIA, S. T.; FURLANETTO, S. M. P. Motile Aeromonas spp. in retail vegetables from São Paulo, Brazil. Revista de Microbiologia, São Paulo, v. 26, n. 1, p. 22-27, 1995.

SAHA, D.; PAL, J. In vitro antibiotic susceptibility of bacteria isolated from EUS-affected fishes in India. Letters in Applied Microbiology, Oxford, v. 34, p. 311-316, 2002.

SCHMIDT,A. S.; BRUUN, M. S.; DALSGAARD, I.; LARSEN, J. L. Incidence, distribution, and spread of tetracycline resistance determinants and integron-associated antibiotic resistance genes among motile aeromonads from a fish farming environment. Applied and Environmental Microbiology, Washington, v. 67, n. 12, p. 5675-5692, Dec. 2001.

Ciênc. agrotec., Lavras, v. 30, n. 6, p. 1211-1217, nov./dez., 2006 
SCHMIDT, A. S.; BRUNN, M. S.; DALSGAARD, I.; PEDERSEN, K.; LARSEN, J. L. Occurence of antimicrobial resistance in fish-pathogenic bacteria associated with four Danish rainbow trout farms. Applied and Environmental Microbiology, Washington, v. 66, n. 11, p. 4908-4915, Nov. 2000.

SON, R.; RUSUL, G.; SAHILAH, A. M.; ZAINURI, A.; RAHA, A. R.; SALMAH, I. Antibiotic resistance and plasmid profile of Aeromonas hydrophila isolates from cultured fish, Telapia (Telapia mossambica). Letters in Applied Microbiology, Oxford, v. 24, p. 479-482, 1997.

SOUSA, J. A.; SILVA-SOUZA, A. T. Bacterial community associated with fish and water from Congonhas river,
Sertaneja, Paraná, Brazil. Brazilian Archives of Biology and Technology, Curitiba, v. 44, n. 4, p. 373-381, Dec. 2001.

SUGITA, H.; TANAKA, K.; YOSHINAMI, M.; DEGUSHI, Y. Distribution of Aeromonas species in the intestinal tracts of river fish. Applied and Environmental Microbiology, Washington, v. 61, n. 11, p. 4128-4130, Nov. 1995.

VIVEKANANDHAN, G; SAVITHAMANI, K.; HATHA, A. A. M.; LAKSHMANAPERUMALSAMY, P. Antibiotic resistance of Aeromonas hydrophila isolated from marketed fish and prawn of South India. International Journal of Food Microbiology, Amsterdam, v. 76, p. 165168, 2002. 